\title{
Effects of Distance between Home Plate and the Backstop on Self-confidence of Intercollegiate Baseball Players
}

\author{
Darrin Sorrells*, Kyle Kempf \\ University of Southern Indiana, 8600 University Boulevard, Evansville, IN, USA
}

Copyright $(2017$ by authors, all rights reserved. Authors agree that this article remains permanently open access under the terms of the Creative Commons Attribution License 4.0 International License

\begin{abstract}
The purpose of the study was to determine whether the distance between home plate and the backstop may impact the levels of self-confidence of intercollegiate baseball pitchers when throwing their pitches. The null hypothesis $\left(\mathrm{H}_{0}\right)$ is that there is no difference in baseball pitchers' levels of self-confidence when the distance between home plate to the backstop is greater than 25 feet. The research hypothesis $\left(\mathrm{H}_{1}\right)$ is that there is a statistically significant difference in baseball pitchers' levels of self-confidence when the distance between home plate to the backstop is greater than 25 feet. The participants in the study were eleven $(\mathrm{N}=11)$ baseball pitchers who were members of the same intercollegiate baseball team in the United States. The research team concludes that there was a slight decrease in self-confidence overall when the backstop was more than 25 feet away from home plate, but the decline in the level of self-confidence for the participants seemed to be minor. The decline in self-confidence with a distance of greater than 25 feet was statistically significant for the best pitch but not statistically significant for the second best pitch.
\end{abstract}

Keywords Self-confidence of College Baseball Pitchers

\section{Introduction}

\section{Importance of Facility Design and Features}

Each baseball stadium is unique. Whether it is a professional team's facility located in the heart of a vibrant downtown metropolitan area or it is a small intercollegiate stadium on a college campus that is located next to the college's soccer pitch and behind academic buildings, each seems to have its own unique history and story to tell. While the primary attraction for baseball fans is the game itself, the ambience of the stadium and the sights and sounds associated help to provide the overall experience for fans. When fans enter a baseball stadium, they quickly see concession areas where they can purchase such baseball food staples as hot dogs and peanuts. They will more than likely hear music and game-related announcements from the public address system. Once seated, fans will see the field. At first glance, one might believe that a baseball field is just a baseball field. Each stadium has four bases and a pitching mound. Upon closer observation, however, baseball fans will recognize the originality and unique design and layout of each facility. For example, is the playing surface natural grass or an artificial surface? What are the outfield dimensions? How high is the outfield wall? Does the facility have a lot of room in foul territory? Where are the bullpens located? Does the wind typically blow out or in toward home plate? Though seemingly unrelated to how well or poorly players play baseball, the answers to these questions may well impact certain aspects of player performance.

\section{Definitions}

\section{Defining Approach, Performance and Self-Confidence}

Many baseball players have their own unique pre-game rituals. Some like listening to music to get prepared while others may engage in imagery and visualization techniques. Regardless of the strategies that may be utilized, the overall goal is the same. Players want to be physically and mentally prepared to compete at their peak levels; they want to have the best approaches toward the game in order to be competitive. For the purpose of this study, approach is defined as the mental and physical strategies utilized in order to perform. "A pre-performance routine can be defined as a systematic sequence of motor, emotional, and cognitive behaviors that are performed immediately before the execution of self-paced tasks" (Otto, Gentner, Czech, Burdette, \& Biber, 2014, p. 85). Once baseball players are prepared, they hope to be ready to perform to the best of their abilities while also understanding that even elite baseball players can be far from perfect in performance over the course of any game. Players with such "balanced" mental dispositions and who focus primarily on what they actually can control rather than external factors out of their control will usually be more resilient when such setbacks occur; thus, 
they tend to possess higher internal loci of control (Huber, 2013).

When players perform, they execute their skills and abilities to compete. For the purpose of this study, performance is related to how well a player executes based on statistical data and outcomes, such as the number of home runs a hitter has during a season or the earned run average (ERA) of a pitcher. A recent concept related to performance within sports, business, and the arts is superior performance intelligence (SPI). According to Graham Jones (2012), commonalities of sustained performance by elite individuals who possess high levels of SPI include (1) knowing how to maximize their potential, including stretching themselves to achieve success; (2) knowing how to work with their environment, including having an awareness of what environmental aspects are controllable and which are uncontrollable; and (3) knowing how to deliver high performance, including planning for performance and delivering even under challenging circumstances. Thus, it would seem that baseball players who fully understand the environments that surround them as well as what elements are and are not within their control, will compete at higher performance-levels than players who become too focused or distracted by external environmental factors, such as dimensions and playing surfaces. Even so, at times factors outside of a player's own control, such as unique design features of a sport facility, may still potentially impact overall performance.

In baseball, confidence can be the difference between victory and defeat. Players must believe in their abilities to make correct decisions, execute their physical skills, and attain mental skills such as focusing on attention and managing nervousness. In fact, self-confidence and the outcome of an individual's play seem to be significantly related to performance, with self-confidence oftentimes the deciding factor (Horn, 2008). In interviews conducted with pitchers for this research study, each participant had his own way of defining self-confidence. One pitcher described it as "a sense of knowing you are better than the hitter and knowing that they are not going to hit you." Another pitcher during an interview defined it as "having the ability to throw pitches when needed and not worrying about where the pitch is going." While various descriptions exist, for this study, self-confidence is considered to be a belief in one's ability to execute or perform in a given situation.

\section{Review of Literature}

\subsection{Playing Surface}

One of the facility design features that has been a topic of discussion during the past several years is the actual field playing surface. Certainly the type of surface can impact a ball hit by a batter. A ball hit on artificial turf tends to have a different bounce and trajectory compared to a baseball hit on a natural grass surface. An outfielder potentially might alter his approach toward fielding a ball if playing on artificial turf compared to natural grass. While artificial turf, historically known by many as AstroTurf, was once used frequently when new stadiums were being designed and constructed, its popularity has greatly declined among professional baseball teams since the 1990 's. Of the 30 current Major League Baseball teams, only two are playing on artificial surfaces: the Toronto Blue Jays who play their home games at the Rogers Centre in Toronto, Ontario, Canada and the Tampa Bay Rays who play their home games at Tropicana Field in St. Petersburg, Florida.

Artificial turf had once been very popular during the cookie-cutter era (1960-1980) of baseball stadiums. During that era, stadiums were being designed and built for multipurpose usage for both baseball and football teams, including Cincinnati's Riverfront Stadium, Pittsburgh's Three Rivers Stadium, and Veterans Stadium in Philadelphia (Fried, 2015). "In both their planning and their architecture, these new multipurpose structures were part of America's trend toward modernism. This crop of publically financed stadia was too small for football and too large for baseball" (Smith, 2014, p. 112). Eventually the cookie-cutter era "morphed into the dome era around the same time frame during which the Astrodome (Houston), the Kingdome (Seattle), the Metrodome (Minneapolis), and the SkyDome (Toronto) were built" (Fried, 2015, p. 14). All of the aforementioned dome structures originally had artificial playing surfaces. Artificial surfaces began to be replaced in the 1990's by natural grass surfaces during the next design era, known as the retro era. Retro stadiums, such as Baltimore's Camden Yards and Coors Field in Denver, were designed to provide fans with more of a "throw-back" experience (Fried, 2015). Because older stadiums in the 1940's and 1950's had grass surfaces, the newly-constructed retro era baseball stadiums were also designed with natural grass and/or field turf rather than artificial playing surfaces.

While artificial surfaces have declined greatly in Major League Baseball, they are still prevalent among many intercollegiate athletic teams in the United States. The use of artificial playing surfaces helps college athletic programs to reduce expenses related to upkeep and maintenance and allows teams located in the northern United States to play more home games (Coverston, 2015). One interesting trend among a few college athletic teams is designing stadiums with artificial surfaces of other colors besides green. These colors are usually selected to convey school spirit and to showcase the colors of the home team. In football, for example, Boise State University has a blue artificial playing surface and Eastern Washington University plays on a red artificial surface. As of 2015, only one intercollegiate baseball program had a field of a different color than green: the University of Northwestern Ohio. The team installed new red turf before the start of the 2015 season (Coverston, 2015). While it is very doubtful that such a trend will make its way to Major League Baseball or even Minor League Baseball, it will be interesting to monitor the trend at the intercollegiate level. Such playing surfaces, although innovative, do have 
potential drawbacks, such as providing too much of a home field advantage for the home team due to familiarity with the surface; players who wear similarly-colored uniforms could be challenging for opponents to distinguish from the playing surface (Coverston, 2015).

In addition to the actual turf itself, other areas of the playing surface can also potentially influence a baseball player's approach and performance. The dirt area directly in front of home plate is one area that can impact performance. "By keeping this area moist and a bit softer than the infield, you can slow down the speed of the ball. . . Balls that hit hard, compacted dirt on their way up the middle tend to not only get by the pitcher but by the middle infielder as well" (DiVito, 2013, p. 10). According to the head groundskeeper for the Minnesota Twins Larry DiVito (2013), "it is widely accepted that new or renovated infield skin mixes have silt to clay (SCR) ratios between 0.5 and 1.0. Our SCR here at Target Field is 0.69 " (p. 13). A SCR ratio between 0.5 and 1.0 will generally allow for the baseball to bounce more consistently through the infield (DiVito, 2013). Moreover, it is estimated that it takes more than 550 bags of clay and more than 30 bags of fertilizer to cover the average Major League Baseball natural grass field (Courchaine, 2012). Certainly if a field does not have the requisite amount of these materials, the surface itself may be impacted; thus, performance may be impacted as well.

\subsection{Pitching Mound}

Throughout the history of the game of baseball the pitching mound has also been a significant factor in impacting overall player approach and performance. The current height of a Major League Baseball mound is ten inches. Between 1903 and 1949, Major League stadiums were permitted to have pitching mounds of any height up to 15 inches in elevation. During this time period, mound elevations varied greatly. For example, in 1941, Detroit's Briggs Stadium had a mound of 15 inches, New York's Yankee Stadium's pitching mound was 14 inches in height, Chicago's Comiskey Park had a mound of 12 inches in elevation, and the mound at Griffith Stadium in Washington was only seven inches in height (Kermisch, 2000). The standard elevation of ten inches was implemented in 1969. According to Kermisch (2000), during the 1968 season, pitchers had a dominant season statistically against hitters. As a result, Major League Baseball decided to require all pitching mounds to be the same height of ten inches in an effort to provide less of an advantage for pitchers.

\subsection{Historical Context/Examples}

Forbes Field opened in 1909 and served as the home of Major League Baseball's Pittsburgh Pirates for more than 60 seasons. Historically, Forbes Fields was known more as a "pitcher friendly" ballpark. A review of baseball statistical data seems to support that belief. When it opened in 1909, only Cincinnati's Redleg Field was more spacious. "In the ensuing years, parks in other NL cities varied in size, but
Forbes Field was never less than 457 to center field" (Selter, 2003a, p. 95). While hitters oftentimes struggled to hit homeruns at Forbes Field, throughout the years they did seem to hit a high rate of triples. "Owen Wilson of the 1912 Pirates set the major league single-season record for triples (36) while playing half his games in Forbes Field, and...in 18 seasons (1921-1937) the Pirates led the NL in triples 14 times" (Selter, 2003a, p. 96). One interesting historical note regarding Forbes Field is Babe Ruth hit his final three homeruns of his career at the stadium in 1935. Ruth's last homerun (\#714), which at the time established the all-time Major League Baseball homerun record, totally cleared the wall in right field, a feat which no previous hitter at Forbes Field had ever accomplished (Selter, 2003a).

Yet another classic example of a baseball facility design impacting baseball player approach and performance is the former Sportsman's Park in St. Louis. From 1920-1953, the facility served as the home ballpark for the St. Louis Browns (currently Baltimore Orioles) of Major League Baseball's American League and the St. Louis Cardinals of the National League. During the 1925-26 offseason, the wooden bleachers in the outfield were rebuilt using steel and concrete. The right field seats, totaling nearly 3300 , were covered completely. Thus, the area was thereafter referred to as the Sportsman's Park Right Field Pavilion due to the roofing. The renovation in 1925-26 also resulted in a short right field foul line dimension marked at 310 feet (Selter, 2003b). After a series in July 1929 when the visiting Detroit Tigers homered eight times in four games against the Browns, Browns management decided to help the home team's pitching staff, even though the home team had defeated the visiting Tigers in three of the four games. July 5, 1929 was an off-day for the Browns. On that day, a $21 \frac{1}{2}$ feet tall screen was installed above the wall that existed in right field. "The screen was in play and raised the barrier to RF (right field) homers from 11.5 to 33 feet. The screen ran from the foul line to about right center-near the $354-\mathrm{ft}$. mark, and covered nearly all of right field" (Selter, 2003b, p. 78).

The new screen's effects were quickly felt. One week after the new screen was installed, several players from both the Browns and the visiting team had been denied homeruns, including a ball hit by Babe Ruth (Selter, 2003b). "In the 35 games without the RF screen, the Browns hit 18 homers and the visitors 32. Despite more games with the screen (42), the Browns' homers dropped to four, while the visitors had a more modest decline of 6 to 26" (Selter, 2003b, p. 78). Thus, interestingly, the installation of the screen may have actually had a negative impact on the home team rather than what management had originally wanted. The performance of players from the other tenant of Sportsman's Park, the St. Louis Cardinals, were also impacted historically as well. The screen was in play until the Browns left for Baltimore in 1954. At the end of that season, the Cardinals management decided to remove the screen. "The data for the 1954 season shows (Stan) Musiel would have had 10 more homers without the screen, while Red Schoendiest and Solly Hemus would have had five more apiece" (Selter, 2003b, p. 78). 
After the 1955 season, the Cardinals management decided to erect a newer and higher screen of 37 feet in height in right field; the screen remained for all of the following seasons at the facility.

A more recent example of a baseball facility design impacting player approach and performance is the new Yankee Stadium. The facility was built at a cost of $\$ 1.5$ billion, making the stadium the most expensive ballpark constructed to date in Major League Baseball (Fried, 2015). While the new Yankee Stadium is located directly across the street from the former facility, and it has the exact same dimensions as the old Yankee Stadium, it has had a different impact on the game than its predecessor. "The culprit named by many is a jet stream to right field. . After studying the stadium for several years, various 'experts' concluded that the culprit was not wind but rather the height and shape of the right field wall" (Fried, 2015, p. 138). In fact, the right field wall at the new Yankee Stadium has been listed by some as one of the top ten flaws in stadium design (Top 10 Stadium Design Flaws, 2013). The old Yankee Stadium's right field wall had a slight curve in its design whereas the new facility's right field wall is constructed on a straight line. "A study conducted by AccuWeather in June of 2009 concluded that $20 \%$ of the homeruns hit at the new stadium would have stayed in play at the old ballpark because of the curved right field corner and 10-ft. fences" (Top 10 Stadium Design Flaws, 2013). Interestingly, although the facility yielded a significant number of home runs early in its opening season of 2009 , the number of homeruns hit has declined substantially during recent seasons.

Baseball facility design features that have impacted performance have not been limited to stadiums in the United States. Canadian baseball teams have also historically experienced impacts as well. Built in the 1970's, Olympic Stadium served as the primary venue for the 1976 Summer Olympics. In 1977, the facility became the new home to the former Montreal Expos (current Washington Nationals) of Major League Baseball's National League. The facility remained the home facility for the Expos until the team departed Montreal in 2004. One of the unique design features of Olympic Stadium is its retractable roof that was installed in 1987. Orange in color, the roof is designed of synthetic fiber. The retractable roof is attached to the circular top portion of the stadium. Prior to the installation of the roof, the facility had been an open-air stadium. One early controversy in Olympic Stadium's history occurred in 1977 when Dave Kingman hit a baseball that seemed to be traveling to the outfield seats as a homerun. However, the ball hit the circular concrete rim above the playing field, and the ball was ruled as a foul ball by the umpire. To prevent future instances from occurring, foul territory was designated by a painted line along the circular rim of the stadium (Trudeau, 2011).

The aforementioned historical examples illustrate how a baseball player's overall approach and actual performance at times may be impacted by unique facility design features. For example, if a power hitter from a visiting team is playing in a spacious ballpark that historically tends not to yield a lot of homeruns but is conducive to doubles and triples, such as Forbes Field, he might adjust his approach before the game and even while actually hitting at the plate; thus, the output and his overall performance might be impacted. On the surface it might seem then that a home team holds a home field advantage in baseball over the visiting team because the home team's players are more familiar with their surroundings and the facility's features and nuances. While this familiarity may be somewhat of an advantage, recent research studies actually suggest that it is not statistically a significant advantage in reality. According to Pollard (2002), only about 25 percent of a home team's advantage can be attributed to familiarity with the facility. Moreover, in the sport of baseball, there does not appear to be a significant advantage for home teams when playing in facilities with retractable roofs and when the roofs are closed. Romanowich (2012), found that "there was no difference in winning percentage between when the roof was open or closed" (p. 564). Since the 1950's, home advantage in baseball has actually been lower than other team sports, such as basketball, football, and soccer (M.B. Jones, 2015). One potential explanation for the lower home advantage in baseball is the ways in which teammates interact and engage with one another during competition. In a sport like basketball, for example, teammates who may not be directly involved in a specific play will still need to complement their teammates by positioning themselves for a rebound. Whereas in a sport like baseball, a fly ball to the right fielder will rely almost entirely on that one player to catch the ball. The other eight players on the field really cannot do anything to contribute to the outcome of the play (M.B. Jones, 2015).

While a home team's familiarity of a facility might provide a slight advantage, recent research studies suggest that the actual advantage is not statistically significant for home baseball teams. Therefore, each individual baseball player needs to understand how facility design can potentially influence his own individual performance and potentially the team's overall performance. The player's individual approach may need to be slightly altered or adjusted based on the specific facility design features. Even so, research findings suggest that elite baseball players do not overanalyze situations but rather possess high levels of internal loci of control and understand what factors they can and cannot directly control. Successful baseball players are keenly aware of facility design features and how they approach their actual environments, but they also understand that they are limited in their abilities to control how the design of a facility can potentially influence performance. Elite baseball players are mentally and physically prepared to perform, regardless of the actual playing environment, even if the approach is slightly altered or modified due to the facility's unique design and features.

Despite examples of how facility design features in baseball, such as playing surfaces and outfield dimensions, have potentially impacted approach and performance, there appears to be, however, little research that has been 
conducted related to one feature of baseball facility design: the distance between home plate and the backstop. Specifically, does the perceived distance between home plate and the backstop affect a baseball pitcher's self-confidence when pitching? In turn, a pitcher's level of self-confidence can affect his approach and overall performance.

\section{Purpose of Study}

The purpose of the study was to determine whether the distance between home plate and the backstop may impact the levels of self-confidence of intercollegiate baseball pitchers when throwing their pitches.

\subsection{Null Hypothesis}

The null hypothesis $\left(\mathrm{H}_{0}\right)$ is that there is no difference in baseball pitchers' levels of self-confidence when the distance between home plate to the backstop is greater than 25 feet.

\subsection{Research Hypothesis}

The research hypothesis $\left(\mathrm{H}_{1}\right)$ is that there is a statistically significant difference in baseball pitchers' levels of self-confidence when the distance between home plate to the backstop is greater than 25 feet.

\subsection{Participants}

The participants in the study were eleven $(\mathrm{N}=11)$ baseball pitchers who, at the time of the study, were current members of the same intercollegiate baseball team in the United States.

\section{Methodology}

The study utilized mixed methods, both quantitative and qualitative elements. Each participant completed a questionnaire (see Appendix A) and also participated in an interview with the research team. The questionnaire was completed by each participant before the interview occurred. Each participant submitted the completed questionnaire to the research team prior to the interview. The questionnaire utilized a Likert Scale with scores ranging from 1-10, with 10 representing strongest agreement and 1 representing strongest disagreement. The research team then asked each participant individually a series of questions during the interview (see Appendix B). Questionnaire item responses and oral information gathered during interviews were both reviewed by the research team for analysis and conclusions. Even though it is difficult to make generalized statistical conclusions when a sample size is small, the T-test is typically used with intentional small sample sizes. The T-test was performed for this study using participants' responses to questionnaire items to test the research hypothesis.

\section{Study Assumptions and Limitations}

For the research study it was assumed that each participant would completely and honestly answer items on the questionnaire as well as provide honest responses during interviews. The study was limited in the number of participants $(\mathrm{N}=11)$ and scope (members of the same intercollegiate baseball team). The sample size used for the study was intentionally small due to the nature of the study. The research team wanted the participants to all be pitchers from the same college baseball team because they would have played at the same baseball fields and under the same team's system and coaches. Thus, purposive sampling was selected and was appropriate for the specific nature of the study.

\section{Results}

Eleven $(\mathrm{N}=11)$ intercollegiate baseball pitchers participated in this research study. Three of the participants were starting pitchers while the remaining eight participants were relief pitchers. In an eight-item questionnaire, the pitchers were asked to respond to items assuming that a runner was in scoring position on third base. The responses to the items were scaled from 1-10, with 10 representing strongest agreement and 1 representing strongest disagreement. The participants were also individually interviewed to provide their thoughts on five different items.

Of the pitchers $(\mathrm{N}=11)$ surveyed, 10 considered their best pitch to be a fastball, while one pitcher considered his best pitch to be a curveball. When surveyed what each pitcher considers his second best pitch to be, six pitchers considered their second best pitch to be a slider, two participants decided their second best pitch was a pitch not listed (other), one pitcher considered his to be a fastball, one pitcher considered his to be a curveball, and one pitcher stated change-up (see Figure 1). 


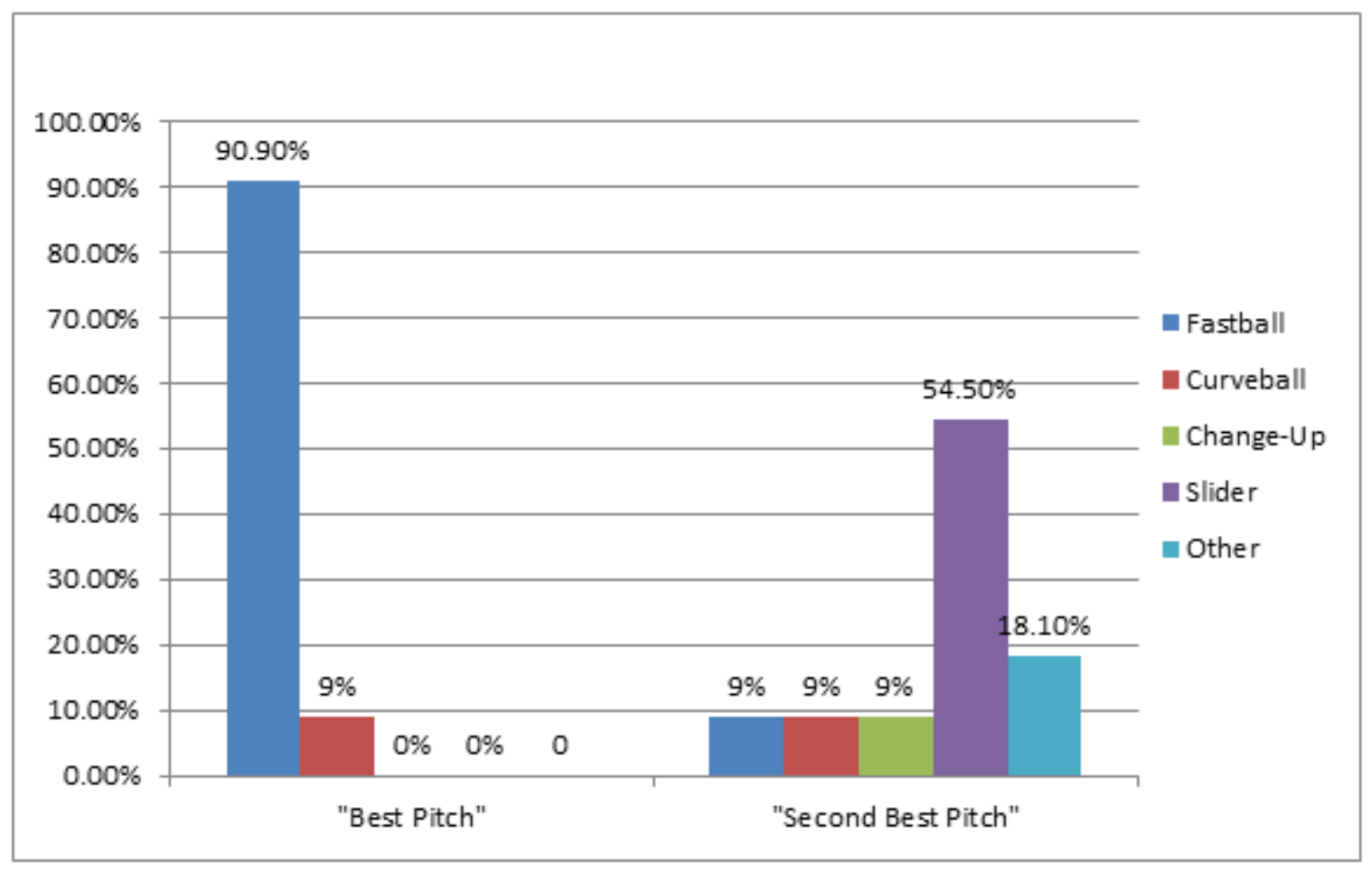

Figure 1. Perceived Best Pitch and Second-Best Pitch

When surveyed how confident they are throwing their best pitch when the distance from home plate to the backstop is less than 25 feet, all participants ( $\mathrm{N}=11$ ) were $100 \%$ confident. In an inverse position, when asked how confident each pitcher is when throwing his best pitch when the distance from home plate to the backstop is more than 25 feet, seven pitchers were $100 \%$ confident, two were $90 \%$ confident, and two were $80 \%$ confident (see Figure 2). Additionally, when asked how confident each pitcher is throwing his second best pitch when the distance from home plate to the backstop is less than 25 feet, six pitchers were still $100 \%$ confident, while three were $90 \%$ confident, and two were $80 \%$. When asked how confident each pitcher is when throwing his second best pitch when the distance from home plate to the backstop is more than 25 feet, three pitchers were $100 \%$ confident, while four were $90 \%$ confident, one was $80 \%$ confident, and three were $70 \%$ confident (see Figure 3).

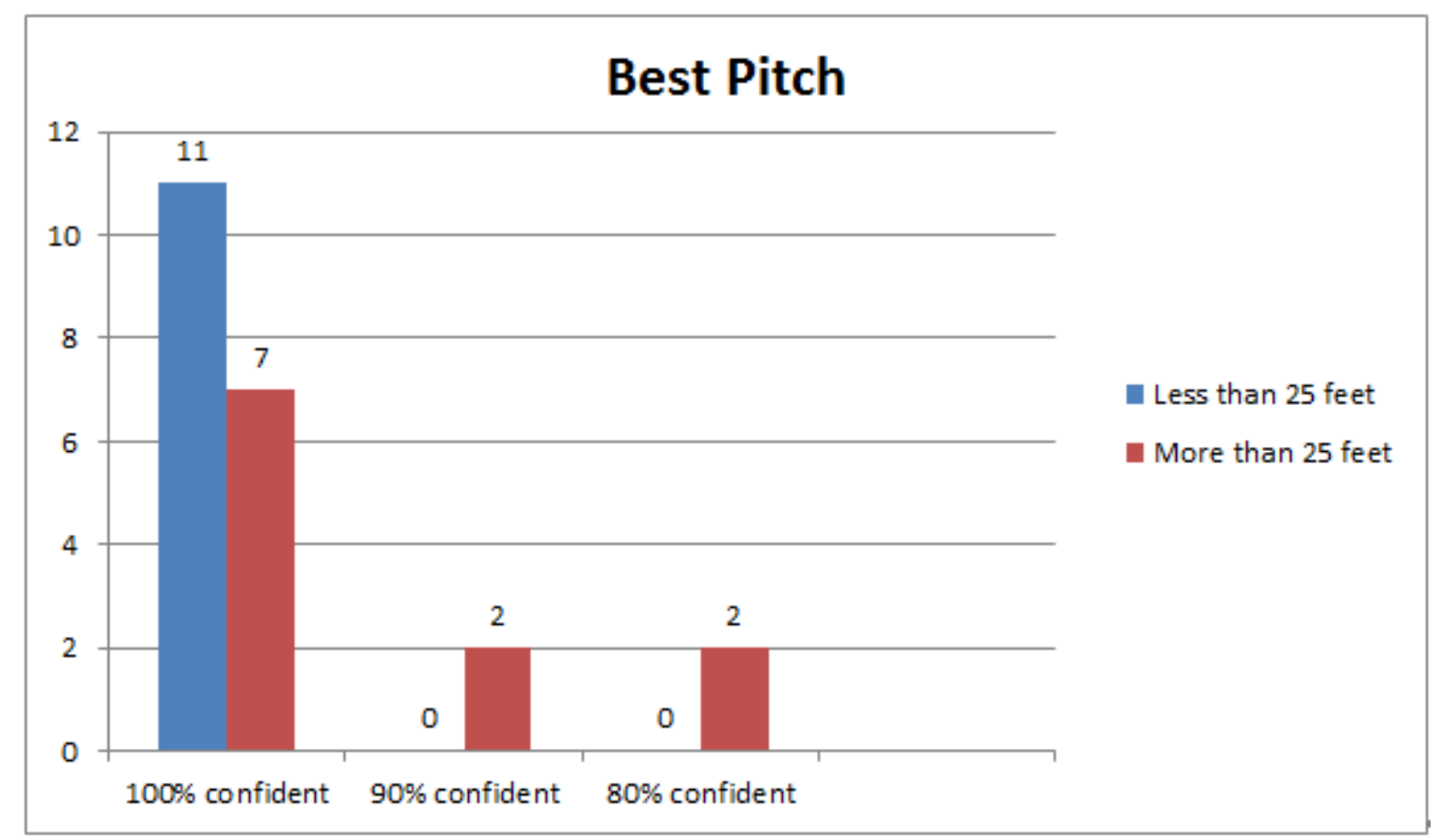

Figure 2. Confidence Throwing Best Pitch 


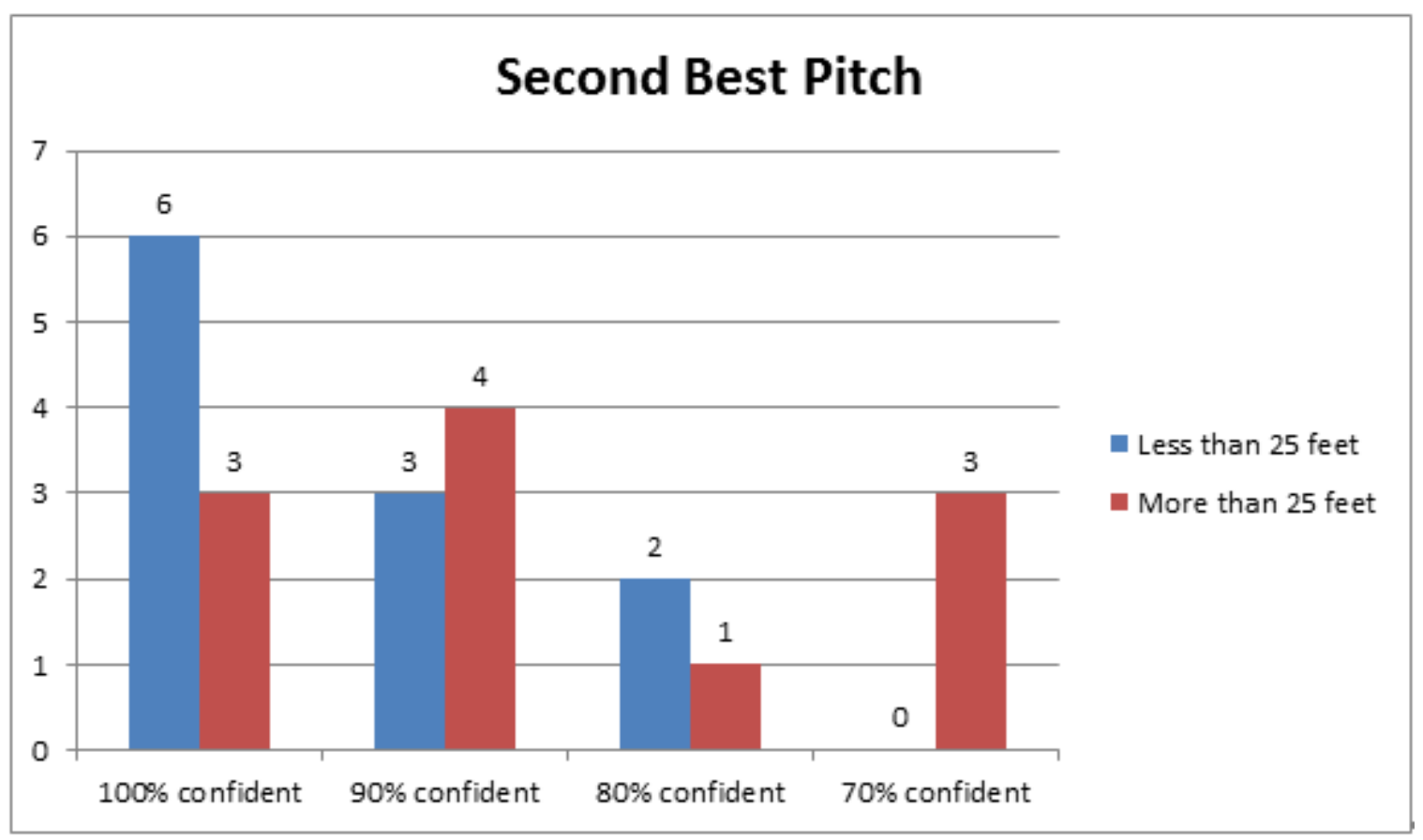

Figure 3. Confidence Throwing Second-Best Pitch

The survey continued to ask the same four questions with a small modification. When surveyed how confident each pitcher is when throwing his best pitch in the dirt to try to get the batter to chase the pitch when the distance from home plate to the backstop is less than 25 feet, two pitchers were $100 \%$ confident, four were $90 \%$ confident, and five were $80 \%$ confident. When asked the same question when the distance from home plate to the backstop is more than 25 feet, one pitcher was $100 \%$ confident, one was $90 \%$ confident, five pitchers felt that they were $80 \%$ confident, three were $70 \%$ confident, and one believed that he was $40 \%$ confident.

On the other hand, when asked the same two questions except changing the pitch from "best pitch" to the "second best pitch," when home plate to the backstop is less than 25 feet, three pitchers were $100 \%$ confident in their abilities, one was $90 \%$ confident, five were $80 \%$ confident, one was $70 \%$ confident, and one pitcher was $60 \%$ confident. When the distance from home plate to the backstop changed to more than 25 feet, when asked the same question, one pitcher was $100 \%$ confident, two were $90 \%$ confident, five pitchers were $70 \%$ confident, two were $60 \%$ confident, and one was only $20 \%$ confident in his ability to execute.

The T-test was performed using Statistical Package for the Social Sciences (SPSS). For this research study, the significance level is .05 $(p<.05)$. Thus, the null hypothesis is rejected when $p<.05$. The results of the T-test suggest that there is not a significant difference in levels of self-confidence when the distance from home plate to the back stop is greater than 25 feet for the second best pitch $(p=.112)$, but there is a significant difference in levels of self-confidence when the distance is greater than 25 feet for the best pitch $(p=.039)$ (see Table 1).
Table 1. Level of Self-Confidence Related to Distance between Home Plate and Backstop

\begin{tabular}{|c|c|}
\hline Type of Pitch & $\begin{array}{c}\text { Distance Between Home Plate and Backstop } \\
\text { Greater than } \mathbf{2 5} \text { feet }\end{array}$ \\
\hline Best Pitch & $\begin{array}{c}p=.039 \\
\text { (statistically significant) }\end{array}$ \\
\hline Second Best Pitch & $\begin{array}{c}p=.112 \\
\text { (not statistically significant) }\end{array}$ \\
\hline
\end{tabular}

\section{Conclusions and Recommendations}

In conclusion, through the survey instrument and individual interviews, the research team believes that there was a slight decrease in self-confidence overall when the backstop was more than 25 feet away from home plate, but the decline in the level of self-confidence for the participants seemed to be minor. Many of the pitchers were very confident in all of their pitches, regardless of the distance from home plate to the backstop or if it was the best or second best pitch. Interestingly, however, when the T-test was conducted, the decline in self-confidence with a distance of greater than 25 feet was statistically significant for the best pitch but not statistically significant for the second best pitch.

During the interviews conducted, the majority of the pitchers stated that they heavily relied on the catcher to block a bad pitch and would put all of their trust in the catcher's ability. During one interview, one pitcher suggested that the distance of the backstop did not bother his self-confidence, even when a runner was on third base in scoring position. However, he believed that his self-confidence could potentially shift late in a game during a pressure situation. Of the eleven participants, all eleven $(\mathrm{N}=11)$ were 100 percent confident with their best pitch when the distance was less 
than 25 feet, but only seven of the eleven were 100 percent confident with their best pitch when the distance from home plate to the backstop was greater than 25 feet. Thus, as reflected in Table 1, the research hypothesis was supported. The greater distance did significantly impact the levels of self-confidence for four of the eleven participants when throwing the best pitch.

One possible explanation for the statistical rejection of the research hypothesis for what was considered the second best pitch for some participants is the nature of the pitch itself. Six of the eleven study participants indicated that their second best pitch was a slider. That particular pitch has a downward trajectory when thrown; thus, it is more likely than a fastball, for example, to go in the dirt when thrown. In turn, it is understandable, then, why some pitchers might feel less confident initially when throwing a slider, regardless of the distance between home plate and the backstop, because they naturally have less control over where the ball will ultimately go. Furthermore, another possible explanation might be some type of self-fulfilling prophecy. If a pitcher initially has identified a pitch as not his best, he already has a belief in his mind that he does not feel as confident throwing that particular pitch compared to what he considers his best pitch. That self-fulfilling prophecy would be magnified when the nature of the pitch itself has a downward trajectory, such as a slider, regardless of the distance between home plate and the backstop.

Future recommendations are for baseball pitchers to understand preferred levels of self-confidence in sport, regardless of facility design and features such as the distance from home plate to the backstop. Sport psychologists, for example, often refer to optimal self-confidence levels for athletes as slightly over-confident. "Optimal self-confidence means being so convinced that you can achieve your goals that you will strive hard to do so" (Weinberg \& Gould, 2015, p. 327). If the study were to be replicated, it would be suggested to expand the sample size and diversify with pitchers from different teams at various levels (amateur, intercollegiate, and professional). It might also be interesting to test to see if there is a difference in levels of self-confidence between starting and relief pitchers.

\section{Significance of the Study}

The study is significant because it makes a unique contribution to the sport of baseball and to the field of sport, exercise, and performance psychology. Research literature related to some baseball dimensions and stadium design features, such as type of playing surface or outfield walls, does exist. However, the distance between home plate and the backstop and the potential impact on a pitcher's approach and self-confidence has not been a topic of substantial study. This study allows baseball pitchers and coaches alike to better understand how the distance between home plate and the backstop may influence a pitcher's selection of pitches and his self-confidence to throw certain pitches.

\section{APPENDIX A-Participant Questionnaire}

\section{"Effects of Distance between Home Plate and the Backstop on Self-Confidence of Intercollegiate Baseball Pitchers"}

\section{Participant Questionnaire}

On a scale of 1-10, 10 representing strongest agreement and 1 representing strongest disagreement, please rate your thoughts regarding the following items from your perspective as a college baseball pitcher.

For each of the following items, assume there is a runner in scoring position on third base.

1. I am confident throwing my best pitch when the distance from home plate to the backstop is less than 25 feet.

$\begin{array}{llllllllll}10 & 9 & 8 & 7 & 6 & 5 & 4 & 3 & 2 & 1\end{array}$

2. I am confident throwing my best pitch when the distance from home plate to the backstop is more than 25 feet.

$\begin{array}{llllllllll}10 & 9 & 8 & 7 & 6 & 5 & 4 & 3 & 2 & 1\end{array}$

3. I am confident throwing my second best pitch when the distance from home plate to the backstop is less than 25 feet.

$\begin{array}{llllllllll}10 & 9 & 8 & 7 & 6 & 5 & 4 & 3 & 2 & 1\end{array}$

4. I am confident throwing my second best pitch when the distance from home plate to the backstop is more than 25 feet.
$\begin{array}{llllllllll}10 & 9 & 8 & 7 & 6 & 5 & 4 & 3 & 2 & 1\end{array}$

5. I am confident throwing my best pitch in the dirt to try to get the batter to chase the pitch when the distance from home plate to the backstop is less than 25 feet.

$\begin{array}{llllllllll}10 & 9 & 8 & 7 & 6 & 5 & 4 & 3 & 2 & 1\end{array}$

6. I am confident throwing my best pitch in the dirt to try to get the batter to chase the pitch when the distance from home plate to the backstop is more than 25 feet.
$\begin{array}{llllllllll}10 & 9 & 8 & 7 & 6 & 5 & 4 & 3 & 2 & 1\end{array}$

7. I am confident throwing my second best pitch in the dirt to try to get the batter to chase the pitch when the distance from home plate to the backstop is less than 25 feet.

$\begin{array}{llllllllll}10 & 9 & 8 & 7 & 6 & 5 & 4 & 3 & 2 & 1\end{array}$

8. I am confident throwing my second best pitch in the dirt to try to get the batter to chase the pitch when the distance from home plate to the backstop is more than 25 feet.

$\begin{array}{llllllllll}10 & 9 & 8 & 7 & 6 & 5 & 4 & 3 & 2 & 1\end{array}$

For this study, I consider my "best pitch" to be (choose only one of the following)
- Fast Ball
- Curve Ball
- Change-Up
- Slider 
- Other: (please list)

For this study, I consider my "second best pitch" to be (choose only one of the following)

- Fast Ball

- Curve Ball

- Change-Up

- Slider

- Other: (please list)

For this study, I consider myself to primarily be a: Starting Pitcher or Relief Pitcher

\section{APPENDIX B-Questions Asked During Interviews}

\section{Individual Interview Questions}

Each participant will complete and submit the survey before the individual interview session with the researcher. During the brief interview session, each participant will provide his thoughts related to the items below. Each participant will be interviewed individually, not with other study participants.

1. How would you define self-confidence for a baseball pitcher?

2. Describe an example from your own experience when you pitched in a stadium where the distance from home plate to the backstop was less than 25 feet and the impact, if any, the distance had on your confidence in throwing your best pitch. Please elaborate if it had an impact or no impact at all.

3. Describe an example from your own experience when you pitched in a stadium where the distance from home plate to the backstop was less than 25 feet and the impact, if any, the distance had on your confidence in throwing your second best pitch. Please elaborate if it had an impact or no impact at all.

4. Describe an example from your own experience when you pitched in a stadium where the distance from home plate to the backstop was more than 25 feet and the impact, if any, the distance had on your confidence in throwing your best pitch. Please elaborate if it had an impact or no impact at all.

5. Describe an example from your own experience when you pitched in a stadium where the distance from home plate to the backstop was less than 25 feet and the impact, if any, the distance had on your confidence in throwing your second best pitch. Please elaborate if it had an impact or no impact at all.

\section{REFERENCES}

[1] Courchaine, J. (2012, Fall). Finding the area of a Major League baseball field. Undergraduate Journal of Mathematical Modeling: One + Two. Retrieved from http://scholarcommons.usf.edu/cgi/viewcontent.cgi?article=4 854\&context $=$ ujmm

[2] Coverston, T. (2015, April 3). Will we ever see a blue baseball field? The Baseball Journal. Retrieved from http://www.thebaseballjournal.com/stadiums/will-we-ever-se e-a-blue-baseball-field/

[3] DiVito, L. (2013, March 26). 12 ways a turf manager can help to elevate baseball team defense. SportsTurf. Retrieved from $\mathrm{http://sportsturfonline.com/2013/03/26/12-ways-a-turf-manag}$ er-can-help-to-elevate-baseball-team-defense/

[4] Fried, G. (2015). Managing sport facilities. ( $3^{\text {rd }}$ ed.). Champaign, IL: Human Kinetics.

[5] Horn, T. S. (2008). Advances in sport psychology. $3^{\text {rd }}$ ed.). Champaign, IL; Human Kinetics.

[6] Huber, J. (2013). Applying educational psychology in coaching athletes. Champaign, IL: Human Kinetics.

[7] Jones, G. (2012). The role of superior performance intelligence in sustained success. In S.M. Murphy (Eds.). The Oxford Handbook of Sport and Performance Psychology. New York: Oxford University Press.

[8] Jones, M.B. (2015). The home advantage in Major League Baseball. Perceptual \& Motor Skills: Exercise \& Sport, 791-804.

[9] Kermisch, A. (2000). From a researcher's notebook. The Baseball Research Journal, 29, 126-128.

[10] Otto, J., Genter, N, Czech, D., Burdette, T., \& Biber, D. (2014). Baseball pitchers pre-performance. Journal of Excellence, 16, 84-97.

[11] Pollard, R. (2002). Evidence of a reduced home advantage when a team moves to a new stadium. Journal of Sports Sciences, 4, 237-248.

[12] Romanowich, P. (2012). Home advantage in retractable-roof baseball stadia. Perceptual \& Motor Skills: Exercise \& Sport, $559-566$

[13] Selter, R. (2003a). Forbe's Field, hitter's nightmare? The Baseball Research Journal, 31, 95-97.

[14] Selter, R. (2003b). Sportsman's Park's right-field pavilion and screen. The Baseball Research Journal, 32, 77-80.

[15] Smith, J.M. (2014, Fall). Ballpark or stadium: Does it matter? A Journal of Baseball History and Culture, 23 (1), 110-118.

[16] Top 10 stadium design flaws. (2013, May 17). Real Clear Sports. Retrieved from http://www.realclearsports.com/lists/stadium_design_flaws/y ankee_right_field.html?state=play

[17] Trudeau, C. (2011, Fall). Out of here: Home runs in Canada. The Baseball Research Journal, 40(2). Retrieved from http://sabr.org/research/out-here-home-runs-canada

[18] Weinberg, R.S., \& Gould, D. (2015). Foundations of sport and exercise psychology. (6 $6^{\text {th }}$ ed.). Champaign, IL: Human Kinetics. 